\title{
Bone Marrow Fat and Hematopoiesis
}

\author{
Huifang Wang ${ }^{\dagger}$, Yamei Leng ${ }^{\dagger}$ and Yuping Gong* \\ Department of Hematology, West China Hospital, Sichuan University, Chengdu, China
}

OPEN ACCESS

Edited by:

Xinhua Qu,

Shanghai JiaoTong University Schoo

of Medicine, China

Reviewed by:

Jan Tuckermann,

Universität UIm, Germany

Tamás Röszer

Universität UIm, Germany

*Correspondence:

Yuping Gong

gongyuping2010@aliyun.com

†These authors have contributed equally to this work

Specialty section:

This article was submitted to

Bone Research,

a section of the journal

Frontiers in Endocrinology

Received: 05 June 2018 Accepted: 05 November 2018 Published: 28 November 2018

Citation:

Wang H, Leng Y and Gong Y (2018)

Bone Marrow Fat and Hematopoiesis.

Front. Endocrinol. 9:694.

doi: 10.3389/fendo.2018.00694
Bone marrow fat cells comprise the largest population of cells in the bone marrow cavity, a characteristic that has attracted the attention of scholars from different disciplines. The perception that bone marrow adipocytes are "inert space fillers" has been broken, and currently, bone marrow fat is unanimously considered to be the third largest fat depot, after subcutaneous fat and visceral fat. Bone marrow fat (BMF) acts as a metabolically active organ and plays an active role in energy storage, endocrine function, bone metabolism, and the bone metastasis of tumors. Bone marrow adipocytes (BMAs), as a component of the bone marrow microenvironment, influence hematopoiesis through direct contact with cells and the secretion of adipocyte-derived factors. They also influence the progression of hematologic diseases such as leukemia, multiple myeloma, and aplastic anemia, and may be a novel target when exploring treatments for related diseases in the future. Based on currently available data, this review describes the role of BMF in hematopoiesis as well as in the development of hematologic diseases.

Keywords: bone marrow fat, hematopoiesis, leukemia, aplastic anemia, multiple myeloma

\section{INTRODUCTION}

Bone marrow fat (BMF) is located in the bone marrow cavity and accounts for $70 \%$ of adult bone marrow volume. It also accounts for approximately $10 \%$ of total fat in healthy adults above the age of 25 years $(1,2)$. Although bone marrow adipocytes (BMAs) are derived from bone marrow mesenchymal stem cells (BMSCs), the origin of BMAs might be heterogeneous (3). BMF has been considered as "inert space filler" for a long period of time (4), and hence its role in the normal development of organisms and in disease has been ignored. More recent work has revealed that BMF plays an important role in energy storage, endocrine function, bone metabolism, and regulation of the growth and metastasis of tumors $(2,5-7)$. Currently, BMF accumulation is thought to be correlated with osteoporosis, aging, type 1 diabetes, Cushing's disease, estrogen deficiency, anorexia nervosa, and bone metastasis in prostate and breast cancers (8-14). BMF thus is gradually being accepted to play an important role in metabolism.

Bone cavities are predominantly filled with active hematopoietic red bone marrow, the volume of which gradually decreases with age and is subsequently replaced with fat (yellow bone marrow) which gradually fills the entire marrow cavity through dynamic and reversible processes $(10,15,16)$. The fat in the bone marrow is different from the subcutaneous and visceral fat and exists in two distinct populations: constitutive marrow adipose tissue (cMAT) and regulated marrow adipose tissue (rMAT). It is hypothesized that cMAT is programmed to develop in a very specific temporal and spatial pattern prior to age 25 and remains preserved upon stress challenges, while rMAT is gradually formed throughout life (17). cMAT contains larger adipocytes, is relatively devoid of active hematopoiesis, and is located in distal skeletal sites (18). In contrast, rMAT is composed of interspersed single adipocytes, and is more closely situated in areas of high bone turnover and is better positioned to actively influence hematopoiesis and/or skeletal remodeling (18). BMF accumulates from birth and happens more rapidly at distal skeletal sites than at proximal skeletal 
sites. Additionally, the accumulation of BMF over time is consistent with the age-related decline of hematopoietic function (19). Therefore, the decrease of hematopoietic activity in bone marrow with age may be related to the accumulation of BMF.

Some molecules are known to play major roles in the development of BMF. Connective tissue growth factor (CTGF) is a key negative regulator of adipocytic differentiation of BMSCs (20). Activation of the nuclear receptor peroxisome proliferator-activated receptor gamma (PPAR- $\gamma$ ) and fibroblast growth factor 21 (FGF21) promotes adipocyte differentiation but is also known to inhibit osteoblast differentiation (21, $22)$. On the other hand, activation of the $W n t / \beta$-catenin and Semaphorin 3A (Sema3A) signaling pathways can stimulate BMSCs to differentiate into osteoblasts and inhibit adipogenesis $(23,24)$. More studies on transcriptional regulators and pathways regulating adipogenesis and osteogenesis are reviewed by Nuttall et al. (25).

BMF constitutes the largest population of cells in the bone marrow cavity, and its relationship with hematopoiesis has attracted further attention in recent years. However, the specific link between BMF and hematopoiesis is not yet clear. In this review, we summarize the relationship between $\mathrm{BMF}$ and the hematopoietic microenvironment, hematopoietic stem/progenitor cells, and various lineages involved in the differentiation of blood cells, as well as the role of BMF in the development of hematologic diseases such as leukemia, aplastic anemia, and multiple myeloma.

\section{BONE MARROW FAT, HEMATOPOIETIC MICROENVIRONMENT, AND HEMATOPOIETIC STEM/PROGENITOR CELLS}

The bone marrow hematopoietic microenvironment, which is also known as the bone marrow hematopoietic niche, consists of marrow stroma cells, the cytokines they secrete, microvessels, and nerves. Intravital microscopy has facilitated intensive study of the bone marrow hematopoietic niche. Using this technique it was found that the bone marrow hematopoietic niche had two distinct states: the homeostatic niche and the reconstituting niche, but the precise definition of these niches remain to be determined (26). The hematopoietic stem cell (HSC) niche is also divided into the endosteal niche and sinusoidal niche. Endosteal niche is localized at the inner surface of the bone cavity, wherein the HSCs are in contact with osteoblasts and might serve as a reservoir for longterm HSCs storage in the quiescent state. The sinusoidal niche, on the other hand, consists of sinusoidal endothelial cell lining blood vessels, which provide an environment for short-term HSCs proliferation and differentiation. Both niches act together to maintain hematopoietic homeostasis $(27,28)$. Hematopoietic stem/progenitor cells further differentiate into two major categories of myeloid progenitor cells and lymphoid progenitor cells. Myeloid progenitor cells have the potential to differentiate into the myeloid lineage, while lymphoid progenitor cells have the potential to differentiate into lymphoid sub-lines (Figure 1).

The bone marrow stroma is a mixture of mesenchymal stem/progenitor cells and their progenies, including adipocytes, osteolineage cells, pericytes, chondrocytes, and fibroblasts (29). BMAs, which are the most abundant type of cells in the bone marrow hematopoietic microenvironment, play a vital role in maintaining balance between proliferation and differentiation of hematopoietic stem/progenitor cells. Spindleshaped $\mathrm{N}$-cadherin ${ }^{+} \mathrm{CD} 45^{-}$osteoblastic cells are arranged on the surface of the bone and constitute a major component of the niche supporting HSCs (30). HSCs are maintained and regulated by various signals and cell types of the surrounding microenvironment. These cell types include the vascular sinusoidal endothelial cells, perivascular BMSCs, mature hematopoietic cells, and non-myelinating Schwann cells. Among these cells, the vascular sinusoidal endothelial cells and perivascular BMSCs support the self-renewal of HSCs by secreting the cytokines chemokine stromal cell-derived factor CXCL12 and stem cell factor (SCF) that play important roles in hematopoiesis, spermatogenesis, and melanogenesis (31). On the other hand, mature hematopoietic cells and nonmyelinating Schwann cells are involved in HSC quiescence and localization through various pathways, including the TGF- $\beta$ and CXCL4 signaling pathways (29). Additionally, osteoblasts, BMSCs, and mature hematopoietic cells support multipotent and committed progenitors and play a crucial role in efficient lymphopoiesis, myelopoiesis, and erythropoiesis (29). BMF gradually accumulates with age; this is accompanied by a decrease in HSCs (32). However, it remains unclear whether there is a direct connection between these two phenomena, and this issue needs further exploration.

The technological advancement of three-dimensional electron microscopy allows the observation of BMAs and their relationship with surrounding tissues. Three-dimensional electron microscopy has revealed that BMAs display hallmarks of metabolically active cells, including polarized lipid deposits, dense mitochondrial networks, and areas of endoplasmic reticulum. Triacylglycerol droplets containing fatty acids are taken up and/or released at three key areas: at the endothelial interface, in the hematopoietic milieu, and on the bone surface (33). This directly demonstrates at the microstructure level that bone marrow adipose tissue is active and is not "inert space filler." In the hematopoietic environment of the proximal tibia, BMAs interact extensively with maturing cells of the myeloid lineage and are closely associated with erythroblast islands (33), providing a spatial basis for the interaction between BMF and HSCs.

BMF, as a part of the hematopoietic niche, affects HSCs proliferation and differentiation by secreting adiponectin, leptin, prostaglandins, IL-6, and other adipocyte-related derived factors (34-41). However, so far, it is not clear, whether these factors are also derived from sources other than BMF and contribute to the effects on HSCs. Adiponectin is a protein hormone which is involved in regulating glucose levels as well as fatty acid breakdown. In humans, it is encoded by the ADIPOQ gene and is produced in the adipose tissue (42). Adiponectin promotes 


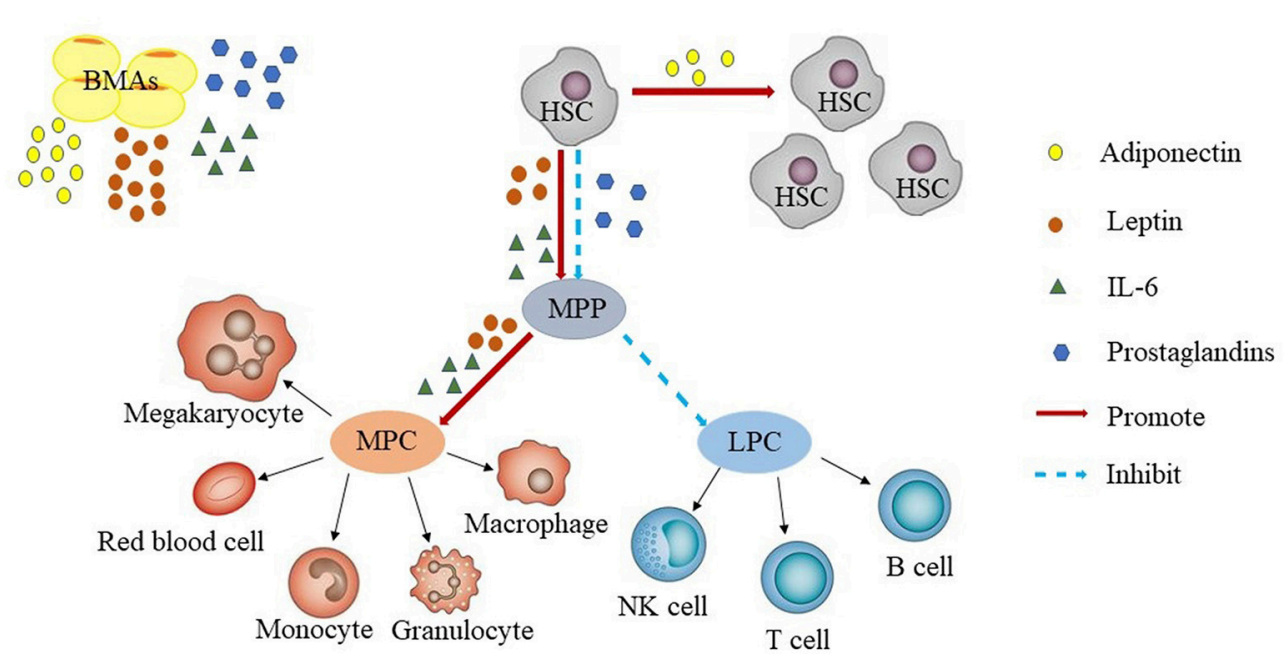

FIGURE 1 | Bone marrow adipocytes and hematopoiesis. BMAs secrete adiponectin, leptin, prostaglandins, IL-6. Adiponectin promotes the proliferation of HSCs. Leptin and IL-6 promotes the differentiation of HSCs, whereas prostaglandins inhibit the proliferation of HSCs. In general, BMAs are more likely to promote HSCs differentiate into myeloid progenitors than into B-lineage progenitors. LPC, lymphoid progenitor cells; MPC, myeloid progenitor cells; HSC, hematopoietic stem cell; LT, long term; MPP, multipotent progenitor; NK, natural killer.

the proliferation of HSCs and maintains their undifferentiated state. HSCs increased through adiponectin were more efficient at hematopoietic reconstitution in lethally irradiated mice through AdipoR1-mediated signaling (34). Leptin a $16-\mathrm{kDa}$ protein produced by adipocytes, is also known to be secreted by $\mathrm{BMF}$ in the bone marrow microenvironment, resulting in high concentrations of this protein in the bone marrow $(43,44)$. Additionally, multiple isoforms of the leptin receptor (LEPR) have been identified, including the long isoform and several isoforms with short cytoplasmic domains $(45,46)$. Leptin independently or synergistically promotes the proliferation of HSCs (35-38), prostaglandins inhibit HSCs through induction of apoptosis $(39,40)$, and IL- 6 promotes the differentiation of HSCs (41) (Figure 1).

The specific role of BMF in regulating the differentiation of HSCs and other bone marrow lineages has not been clarified to date. A study by Tavassoli et al. found that hematopoiesis in the bone marrow of rabbits was enhanced after removal of BMF (47). Naveiras et al. showed that in the adipocyte-rich bone marrow of the mouse tail vertebrae, number of adipocytes from the thoracic to the caudal vertebrae increased while hematopoiesis gradually decreased. Furthermore, this was accompanied with reduced percentage of multipotent, common myeloid, granulocytemonocyte, and megakaryocyte-erythroid progenitors (48). This data indicated a predominantly negative influence of adipocytes on hematopoiesis within the bone marrow microenvironment. Furthermore, the absence of adipocytes in fatless A-ZIP/F1 mice rescued hematopoiesis in the tail, while the use of the PPAR $\gamma$ inhibitor bisphenol-A-diglycidyl-ether (BADGE) prevented bone marrow adipose formation in bone marrow-transplanted mice, enhanced hematopoiesis, and shortened recovery time after hematopoietic transplantation (48). These data indicated that $\mathrm{BMF}$ inhibits bone marrow hematopoiesis. However, it is interesting to note that the HSCs in the caudal vertebrae were quiescent, not senescent, and that they were able to grow faster on exposure to suitable environment (48). Further they also observed that HSCs purified from the caudal vertebrae had higher long-term engraftment rates $(48,49)$. Despite these data, contrary views on the effect of BMF on HSCs have emerged ceaselessly. BMAs have been reported to reappear on the 7 th day after radiation injury, which corresponds to the initiation of hematopoietic proliferation, therefore, BMAs potentially support HSCs (50). Moreover, bone marrow adipocytes have been found to inhibit HSCs differentiation and prolong their survival in vitro (51). BMAs supported hematopoiesis in the homeostatic state in vitro but had no effect on the same in vivo (52). A study by Zhou et al. revealed that BMF from irradiated and non-irradiated mice produced high amounts of SCF, an essential cytokine that plays a pivotal role in HSCs maintenance, which promoted hematopoietic recovery after 5-fluorouracil treatment or irradiation (53). Strikingly, genetic deletion of SCF from adipocytes inhibited hematopoietic regeneration after myeloablation, whereas genetic deletion of the same cytokine from other important cells present in the niche (osteoblasts and endothelial or hematopoietic cells) did not affect hematopoietic recovery after 5-fluorouracil treatment or irradiation. Therefore, SCF secreted by BMF was necessary for the maintenance of hematopoiesis (53). Additionally, it was found that the role of BMF differed in various compartments of the bone marrow in mice. Adipocytes in the tail vertebrae inhibited hematopoiesis by inhibiting angiogenesis in the bone marrow niche after radiation, whereas adipocytes in long bones promoted hematopoietic recovery after radiation, despite two locations acting as an important source of SCF (53). As an important component of the HSC niche, BMF modulates HSC function, but the role of BMF in hematopoiesis remains controversial. For example, Naveiras et al. 
found that BMF significantly inhibits hematopoiesis, and Zhou et al. found that BMF promotes hematopoiesis by secreting SCF. The role of BMF on the hematopoietic microenvironment and on hematopoietic stem/progenitor cells may be distinct in vivo and in vitro, in different species, or in different locations in the same individual, indicating that the connections between BMF and bone marrow hematopoiesis are extremely intricate. In the future, there will be more like-minded scholars cooperating to explore the links between BMF and hematopoiesis.

\section{BONE MARROW FAT, MYELOPOIESIS AND LYMPHOPOIESIS}

BMF gradually accumulates with age and a high-fat diet (10, 54), and is accompanied by a decrease in B-lineage progenitor cells, whereas HSCs are more likely to differentiate into myeloid progenitors than into B-lineage progenitors (54-56), suggesting that BMF may be associated with myelopoiesis and lymphopoiesis. BMF secretes adipocyte-derived soluble factors in vitro that inhibit $\mathrm{B}$ lymphopoiesis, particularly at the stage at which lymphogenic progenitor cells differentiate into preproB cells, and simultaneously promotes the differentiation and subsequent proliferation of HSCs into the myeloid lineage (57). Similarly, it is shown that BMF had a negative effect on the early stages of B lymphocyte proliferation in the bone marrow of elderly people (57). Kennedy et al. revealed that $\mathrm{BMF}$ induces the production of myeloid-derived suppressor cells (MDSCs), particularly in mononuclear cells $\left(\mathrm{CD} 11 \mathrm{~b}^{+} \mathrm{Ly} 6 \mathrm{C}^{+}\right.$ Ly $6 \mathrm{G}^{-}$), which inhibit B lymphopoiesis by producing IL-1 (58). At the same time, BMAs activate the inflammasome, such as the nod-like receptor 3 (NLRP3), and directly inhibit B lymphopoiesis (59). Inflammasome activation is also likely to promote thymic degeneration $(60,61)$ and exert a negative effect on T-lymphocyte proliferation (62). Blocking the NLRP3 inflammasome with glybenclamide inhibited the accumulation of MDSCs and boosted B lymphopoiesis in vitro (59). Furthermore, the deletion of NLRP3 in mice prevented thymic atrophy and the decline of $\mathrm{T}$ lymphopoiesis (62). BMF induces the production of multipotent progenitors by the bone marrow and promotes HSCs differentiation toward the myeloid lineage. It also induces the secretion of granulocyte-colony stimulating factor, monocyte-colony stimulating factor, and granulocyte monocyte-colony stimulating factor by bone marrow stromal cells, thereby negatively regulating B-lineage cell production and lymphopoiesis, and promoting myelopoiesis (58). In rabbits, the inflammatory cytokine S100A9 increases with the accumulation of BMF in the bone marrow and induces the expression of IL6 , TNF, and IL-1 $\beta$ in bone marrow myeloid cells. However, it is not clear whether the increase of S100A9 is directly related to the accumulation of BMF (59). Naveiras et al. showed that removal of adipocytes from bone marrow in mice led to an increase in hematopoiesis, including $\mathrm{B}$ lymphopoiesis (48). Studies on the toxicant tributyltin (TBT) showed that TBT exposure induces bone marrow adipogenesis and activates $\operatorname{PPAR} \gamma$ in the bone marrow, resulting in a decrease in peripheral B lymphocytes (63). Thiazolidinediones such as troglitazone and the tyrosine analog GW7845 have been shown to activate PPAR $\gamma$ and induce pre-B apoptosis by upregulating NF- $\mathrm{BB}$ (64). Adiponectin secreted by BMF in young rabbits could negatively and selectively influence lymphopoiesis by inducing prostaglandin synthesis (40). This effect was most apparent in early lymphoid progenitors, and cyclooxygenase inhibitors were shown to abrogate the response of early lymphoid progenitors to adiponectin in stromal cell-containing cultures (40). Another BMF adipokine, leptin, has the opposite effect on lymphopoiesis (37). Leptin promotes differentiation and proliferation of the lymphoid lineage, and is also helpful in promoting myelopoiesis (36). In $d b / d b$ mice, wherein the LEPR is truncated, the steadystate levels of peripheral blood B cells and CD4-expressing $\mathrm{T}$ cells are dramatically reduced $(36,38)$. However, there are other theories regarding the role of BMF in myelopoiesis. BMF hampered granulopoiesis through neuropilin-1(NP-1)induced granulocyte-colony stimulating factor inhibition and dexamethasone-induced multinuclear granulocyte proliferation by the downregulation of NP-1 (65). Preadipocytes in the bone marrow therefore appear to contribute to granulopoiesis during the fibrocytic stage and become inactive during hematopoiesis when they are converted to adipocytes (66). The study by Naveiras et al. also found that BMF suppresses bone marrow hematopoiesis, including myelopoiesis (48). An exploration of the mechanism underlying the side effect of rosiglitazone on the bone marrow demonstrated that it inhibits myeloid differentiation of HSCs after stress. Rosiglitazone exerts this effect partially by inducing bone marrow adipogenesis and by targeting the bone marrow microenvironment. The selective PPAR $\gamma$ antagonist BADGE may be able to partially reverse these effects, however, PPAR $\gamma$ is also expressed in myeloid cells with profound effects, and some of these effects could also be cellautonomous in myeloid cells (49). Thus, so far, the role of BMF in myelopoiesis is complex, still unclear, and controversial and may be mediated by multiple mechanisms of action.

\section{BONE MARROW FAT AND ERYTHROPOIESIS}

As early as 1978, Ambika et al. revealed through a study on a group of rabbits that the long-term use of phenylhydrazine induces hemolysis and stimulates erythropoiesis, which in turn stimulates the lipolysis of BMAs (67). This suggested, for the first time, that BMF is associated with erythropoiesis and may be involved in metabolic processes that support hematopoietic function. BMF accumulation leads to anemia in patients with reduced leg loading, which may impair hematopoiesis in two ways: first, by occupying hematopoietic space, and second, by directly interfering with hematopoiesis via paracrine action within the bone marrow microenvironment (68). Robles et al. used a three-dimensional electron microscope to observe the bone marrow of rodents and found that BMAs interact with the phagocytic reticular macrophages of the erythroblast islands, which provided a spatial basis for the role of BMAs in erythropoiesis (33). It has been estimated that a single BMA is capable of interacting with more than 100 hematopoietic 
cells through both direct cell-cell contact and indirect signals via binding with the core macrophage of erythroblast islands $(33,69,70)$. Erythrocytes develop and mature in the erythroblast islands (69). Immature islands are often distant from bone marrow sinusoids and migrate toward the sinusoid when the erythrocytes mature (69). Therefore, BMAs may help deliver energy to distant, immature red blood cell islands, thereby supporting the maturation of red blood cells. This is consistent with previous animal experiments in which the sizes of BMAs were shown to rapidly reduce during active erythropoiesis after phenylhydrazine-induced anemia or severe blood loss $(67,71)$. A recent article reported that the use of erythropoietin to stimulate high-fat diet-fed mice caused an increase in the hematocrit values accompanied by a decrease in bone marrow adipose tissue and the disappearance of adipose tissue (72). However, more research is still needed in the future to identify the signaling pathway/s linking BMF and erythropoiesis.

\section{BONE MARROW FAT AND HEMATOLOGIC DISEASES}

\section{Bone Marrow Fat and Leukemia}

In normal hematopoiesis, the LEPR is expressed in $\mathrm{CD} 34^{+}$ cells, and leptin was found to induce the proliferation and differentiation of these cells (73). Primary acute promyelocytic leukemia (APL) cells express high levels of the long isoform of the LEPR. BMAs produce membrane-bound leptin that participates in the bone marrow cytokine network, regulate the proliferation, survival, and apoptosis of APL cells via direct cell-to-cell contact, and prevent APL cells from drug-induced apoptosis (74). Connective tissue growth factor promotes the differentiation of BMSCs into adipocytes, which produce leptin in the bone marrow, thereby promote leukemic cell engraftment and growth within the bone marrow niche (20).

BMF protects acute lymphoblastic leukemia (ALL) cells from apoptosis induced by various chemotherapeutic agents, although the mechanism of protection is not yet known (75, 76). Subsequent studies demonstrated that ALL cells induce an oxidative stress response in adipocytes, which promotes the resistance of ALL cells to daunorubicin, an anthracycline antileukemia drug $(77,78)$. Adipocytes confer dexamethasone (a cortical hormone drug which is often used to treat chronic lymphocytic leukemia) resistance to chronic lymphocytic leukemia cells by providing lipid factors. BMF supports the survival and proliferation of acute myeloid leukemia (AML) blast cells (79). A possible mechanism for this may be the induction of lipolysis of triglycerides stored within BMAs into fatty acids, which are then released into the bone marrow microenvironment in a process dependent on the chaperone protein fatty acid binding protein-4 (80). Ultimately, fatty acids are metabolically beneficial for the survival and proliferation of AML cells (80). Recent studies have investigated the correlation between BMA morphology and the prognosis of patients with AML. These studies have confirmed that in AML patients, an increase in small BMAs, rather than total BMAs, is associated with poor prognosis (81). Lu et al. demonstrated that growth differentiation factor 15 secreted by leukemia cells induced the transformation of large BMAs into small BMAs, which in turn could promote leukemic cell growth (82). Almost at the same time, other researchers reported opposite findings - that a decrease in adipocyte volume in patients with complete remission from AML is closely related to long-term recurrence-free survival. Growth differentiation factor 15, which is secreted by marrow mononuclear cells in response to chemotherapy and partially blocks adipogenesis, may exert synergistic effects on strengthening chemotherapeutic efficacy and may be used in predicting good outcomes for patients with AML during complete remission (83). These observations suggest that AML interrupts adipogenesis in red bone marrow, leading to impaired myelo-erythroid maturation (84). In vivo, administration of PPAR $\gamma$ agonists have been shown to induce bone marrow adipogenesis, rescuing healthy hematopoietic maturation and repressing leukemic growth (84). These seemingly contradictory conclusions suggest that more rational experiments are needed to explore the role of GDF1 in adipogenesis and AML. Searching for a signaling pathway that disrupts the interaction between leukemic cells and adipocytes may be considered a new approach for targeted therapy against leukemia and combating drug resistance.

\section{Bone Marrow Fat and Multiple Myeloma}

$\mathrm{BMF}$ plays a role in the proliferation, apoptosis, and migration of multiple myeloma (MM) cells in the bone marrow microenvironment (85). However, BMAs disappear during disease progression, while other stromal cells (endothelial cells, fibroblasts) are still present and are activated. This suggests that the role of BMAs is mainly limited to the initial stage of the disease before the remodeling of the bone marrow microenvironment occurs (85). BMAs are the only cells that secrete leptin in the MM microenvironment, and the addition of leptin leads to a slight increase in the proliferation of MM cells in vitro, which participate in these processes by affecting diffusion (85). Leptin serum levels are elevated in patients with MM at the time of diagnosis, but these levels did not increase with the progression of MM. Moreover, leptin levels decreased after treatment (86). Studies have found that the expression of LEPRs on MM cells can predict the response of patients to thalidomide treatment (87). BMF upregulates the expression of autophagic proteins in $\mathrm{MM}$ cells by secreting adipocyte-derived factors, such as leptin and resistin, that leads to the suppression of caspase cleavage and apoptosis, and ultimately protect MM cells from chemotherapy-induced apoptosis (88). Resistin protects MM cells from chemotherapy-induced apoptosis by inhibiting chemotherapy-induced caspase cleavage via the NF- $\kappa \mathrm{B}$ and phosphoinositide 3 kinase (PI3K)/Akt signaling pathways and by enhancing the expression of ATP-binding cassette (ABC) transporters in myeloma cells via demethylation of the $\mathrm{ABC}$ gene promoter (89). However, resistin is secreted not only by BMF but also by monocytes, macrophages, spleen, and bone marrow cells (90). Therefore, further studies are needed to differentiate the effect of resistin secreted by the BMF from the effect of resistin secreted by other stromal cells on myeloma growth and survival (89). 


\section{Bone Marrow Fat and Aplastic Anemia}

Aplastic anemia (AA) is a complex bone marrow failure syndrome characterized by extremely hypoplastic bone marrow and peripheral blood pancytopenia. One of the key pathogenic factors for $\mathrm{AA}$ is the alteration of the hematopoietic microenvironment (91). It is known that the osteogenesis and adipogenesis of BMSCs are well balanced in normal bone marrow, and that disrupting this balance leads to disease (92, 93). Interestingly, in the bone marrow of patients with $\mathrm{AA}$, the number of adipocytes has been observed to be higher, while the number of osteoblasts is lower (94). Thus, the reduction of these cells would affect normal hematopoiesis. Clinical studies have suggested that arsenic trioxide (ATO) is clinically effective in treating patients with $\operatorname{AA}(95,96)$. Furthermore, studies have demonstrated that BMSCs from patients with $\mathrm{AA}$ are prone to differentiation into adipocytes rather than into osteoblasts in vitro $(97,98)$, and that treatment with arsenic trioxide could partially restore the unbalanced differentiation of BMSCs (98). This suggests that arsenic trioxide administration, which improves the balance between osteogenic and adipogenic differentiation, may be a novel therapeutic approach for AA. miRNA-204 has been shown to inhibit osteogenic differentiation and promote adipogenesis of BMSCs by directly inhibiting Runx2, providing a novel therapeutic method for the treatment of diseases with unbalanced osteogenic and adipogenic differentiation (98). Wnt signaling inhibits the differentiation of BMSCs into adipocytes (99). A Wnt signal activator combined with cyclosporine $\mathrm{A}$ has been shown to be more effective in treating AA than cyclosporine A only in mouse models, implying that Wnt signaling could inhibit the differentiation of bone marrow BMSCs into adipocytes and improve bone marrow hematopoiesis (100). This confirms the importance of BMF in the pathogenesis of AA. The transcription factor GATA-2 is expressed in HSCs and early hematopoietic progenitors and plays a crucial role in hematopoiesis (101). A decrease in GATA-2 level affects the proliferation and survival of HSCs $(102,103)$. GATA-2 mRNA level was found to be significantly lower in AA patients than in normal individuals $(104,105)$. GATA-2 is also expressed in preadipocytes and inhibits terminal differentiation into mature adipocytes by suppressing PPAR $\gamma$ (106). GATA-2 expression was significantly reduced in BMSCs in patients with AA, whereas PPAR $\gamma$ expression was significantly higher in AA patients than in normal subjects (107). Therefore, GATA2 participates not only in the generation and maintenance of HSCs but also in the regulation of the hematopoietic microenvironment (108). Identifying the mechanisms by which GATA-2 regulates HSCs and bone marrow BMSCs may be useful

\section{REFERENCES}

1. Fazeli PK, Horowitz MC, MacDougald OA, Scheller EL, Rodeheffer MS, Rosen CJ, et al. Marrow fat and bone-new perspectives. J Clin Endocrinol Metab. (2013) 98:935-45. doi: 10.1210/jc.2012-3634

2. Cawthorn WP, Scheller EL, Learman BS, Parlee SD, Simon BR, Mori $\mathrm{H}$, et al. Bone marrow adipose tissue is an endocrine organ in developing novel therapeutic approaches for bone marrow failure syndrome.

\section{CONCLUSION}

BMAs in the hematopoietic microenvironment influence the hematopoietic process through space support, production of derived cells (MDSCs), and secretion of adipocyte-related derived factors (adiponectin, leptin, prostaglandins, and IL-6). The exact role of BMF in hematopoiesis is not yet clear because of the fractious connection between BMF and other cells in the hematopoietic microenvironment as well as hematopoietic stem/progenitor cells. The heterogeneity of HSCs indicates that the hematopoietic niche supporting HSCs function may have a matching heterogeneity potential (109). As an important part of the HSC niche, it is not clear whether BMF is heterogeneic and how it plays a role in different hematopoietic niches such as the endosteal niche and the sinusoidal niche. It is important to explore the role of different BMAs in hematopoiesis, including the location and species of BMF in future studies. It is also meaningful to explore the effect of BMF in hematopoiesis in different hematopoietic states, such as the homeostatic state and stressing state, in vitro and vivo. By exploring the link between $\mathrm{BMF}$ and the neighboring cell populations in the hematopoietic niche, the current understanding of the complex relationship between BMF and hematopoiesis may be improved. Research on the interactions between adipocyte-derived factors and other signaling factors in the bone marrow microenvironment and their role in hematopoiesis and hematologic diseases will facilitate the discovery of new methods in the field of hematological diseases.

\section{AUTHOR CONTRIBUTIONS}

HW and YL contributed to writing, and YG contributed to editing this work.

\section{FUNDING}

The work was supported by the Foundation of the Science \& Technology Department of Sichuan Province (NO. 2015SZ02345), Foundation of Science and Technology Bureau of Chengdu (NO. 2016-HM01-00001-SF).

\section{ACKNOWLEDGMENTS}

The author thanked the other colleagues of the team for their ideas on the review. that contributes to increased circulating adiponectin during caloric restriction. Cell Metab. (2014) 20:368-75. doi: 10.1016/j.cmet.2014. 06.003

3. Li Q, Wu Y, Kang N. Marrow adipose tissue: its origin, function, and regulation in bone remodeling and regeneration. Stem Cells Int. (2018) 2018:7098456. doi: 10.1155/2018/70 98456 
4. Guerra D, Paiva AE, Sena I, Azevedo PO, Jr. Batista ML, Mintz A, et al. Adipocytes role in the bone marrow niche. Cytometry A (2018) 93:167-71. doi: $10.1002 /$ cyto.a. 23301

5. Devlin MJ. Why does starvation make bones fat? Am J Hum Biol. (2011) 23:577-85. doi: 10.1002/ajhb.21202

6. van der Eerden B, van Wijnen A. Meeting report of the 2016 bone marrow adiposity meeting. Adipocyte (2017) 6:304-13. doi: 10.1080/21623945.2017.1313374

7. Morris EV, Edwards CM. Bone marrow adipose tissue: a new player in cancer metastasis to bone. Front Endocrinol. (Lausanne) (2016) 7:90. doi: 10.3389/fendo.2016.00090

8. Justesen J, Stenderup K, Ebbesen EN, Mosekilde L, Steiniche T, Kassem M. Adipocyte tissue volume in bone marrow is increased with aging and in patients with osteoporosis. Biogerontology (2001) 2:165-71. doi: 10.1023/A:1011513223894

9. Devlin MJ, Cloutier AM, Thomas NA, Panus DA, Lotinun S, Pinz I, et al. Caloric restriction leads to high marrow adiposity and low bone mass in growing mice. J Bone Miner Res. (2010) 25:2078-88. doi: 10.1002/jbmr.82

10. Takeshita S, Fumoto T, Naoe Y, Ikeda K. Age-related marrow adipogenesis is linked to increased expression of RANKL. J Biol Chem. (2014) 289:16699710. doi: 10.1074/jbc.M114.547919

11. Geer EB, Shen W, Strohmayer E, Post KD, Freda PU. Body composition and cardiovascular risk markers after remission of Cushing's disease: a prospective study using whole-body MRI. J Clin Endocrinol Metab. (2012) 97:1702-11. doi: 10.1210/jc.2011-3123

12. Botolin S, McCabe LR. Bone loss and increased bone adiposity in spontaneous and pharmacologically induced diabetic mice. Endocrinology (2007) 148:198-205. doi: 10.1210/en.2006-1006

13. Hardaway AL, Herroon MK, Rajagurubandara E, Podgorski I. Marrow adipocyte-derived CXCL1 and CXCL2 contribute to osteolysis in metastatic prostate cancer. Clin Exp Metastasis (2015) 32:353-68. doi: $10.1007 /$ s10585-015-9714-5

14. Templeton ZS, Lie WR, Wang W, Rosenberg-Hasson Y, Alluri RV, Tamaresis JS, et al. Breast cancer cell colonization of the human bone marrow adipose tissue niche. Neoplasia (2015) 17:849-61. doi: 10.1016/j.neo.2015.11.005

15. Tavassoli M, ed. Handbook of the Hemopoietic Microenvironment. Clifton, NJ: Humana Press (1989).

16. Calvo W, Fliedner TM, Herbst E, Hugl E, Bruch C. Regeneration of bloodforming organs after autologous leukocyte transfusion in lethally irradiated dogs. II. Distribution and cellularity of the marrow in irradiated and transfused animals. Blood (1976) 47:593-601.

17. Scheller EL, Rosen CJ. What's the matter with MAT? Marrow adipose tissue, metabolism, and skeletal health. Ann N Y Acad Sci. (2014) 1311:14-30. doi: $10.1111 /$ nyas. 12327

18. Scheller EL, Doucette CR, Learman BS, Cawthorn WP, Khandaker S, Schell B, et al. Region-specific variation in the properties of skeletal adipocytes reveals regulated and constitutive marrow adipose tissues. Nat Commun. (2015) 6:7808. doi: 10.1038/ncomms8808

19. Ambrosi TH, Scialdone A, Graja A, Gohlke S, Jank AM, Bocian C, et al. Adipocyte accumulation in the bone marrow during obesity and aging impairs stem cell-based hematopoietic and bone regeneration. Cell Stem Cell (2017) 20:771-84.e6. doi: 10.1016/j.stem.2017.02.009

20. Battula VL, Chen Y, Cabreira MG, Ruvolo V, Wang Z, Ma W, et al. Connective tissue growth factor regulates adipocyte differentiation of mesenchymal stromal cells and facilitates leukemia bone marrow engraftment. Blood (2013) 122:357-66. doi: 10.1182/blood-2012-06437988

21. Akune T, Ohba S, Kamekura S, Yamaguchi M, Chung UI, Kubota N, et al. PPARgamma insufficiency enhances osteogenesis through osteoblast formation from bone marrow progenitors. J Clin Invest. (2004) 113:846-55. doi: 10.1172/JCI19900

22. Wan Y. Bone marrow mesenchymal stem cells: fat on and blast off by FGF21. Int J Biochem Cell Biol. (2013) 45:546-9. doi: 10.1016/j.biocel.2012.12.014

23. Day TF, Guo X, Garrett-Beal L, Yang Y. Wnt/beta-catenin signaling in mesenchymal progenitors controls osteoblast and chondrocyte differentiation during vertebrate skeletogenesis. Dev Cell (2005) 8:739-50. doi: 10.1016/j.devcel.2005.03.016
24. Hayashi M, Nakashima T, Taniguchi M, Kodama T, Kumanogoh A, Takayanagi H. Osteoprotection by semaphorin 3A. Nature (2012) 485:69-74. doi: 10.1038/nature11000

25. Nuttall ME, Shah F, Singh V, Thomas-Porch C, Frazier T, Gimble JM. Adipocytes and the regulation of bone remodeling: a balancing act. Calcif Tissue Int. (2014) 94:78-87. doi: 10.1007/s00223-013-9807-6

26. Lassailly F, Foster K, Lopez-Onieva L, Currie E, Bonnet D. Multimodal imaging reveals structural and functional heterogeneity in different bone marrow compartments: functional implications on hematopoietic stem cells. Blood (2013) 122:1730-40. doi: 10.1182/blood-2012-11-467498

27. Rosen CJ, Ackert-Bicknell C, Rodriguez JP, Pino AM. Marrow fat and the bone microenvironment: developmental, functional, and pathological implications. Crit Rev Eukaryot Gene Expr. (2009) 19:109-24. doi: 10.1615/CritRevEukarGeneExpr.v19.i2.20

28. Guerrouahen BS, Al-Hijji I, Tabrizi AR. Osteoblastic and vascular endothelial niches, their control on normal hematopoietic stem cells, and their consequences on the development of leukemia. Stem Cells Int. (2011) 2011:375857. doi: 10.4061/2011/375857

29. Sarkaria SM, Decker M, Ding L. Bone marrow micro-environment in normal and deranged hematopoiesis: opportunities for regenerative medicine and therapies. Bioessays (2018) 40:3. doi: 10.1002/bies.201700190

30. Zhang J, Niu C, Ye L, Huang H, He X, Tong WG, et al. Identification of the haematopoietic stem cell niche and control of the niche size. Nature (2003) 425:836-41. doi: 10.1038/nature02041

31. Kim JY, Choi JS, Song SH, Im JE, Kim JM, Kim K, et al. Stem cell factor is a potent endothelial permeability factor. Arterioscler Thromb Vasc Biol. (2014) 34:1459-67. doi: 10.1161/ATVBAHA.114.303575

32. Tuljapurkar SR, McGuire TR, Brusnahan SK, Jackson JD, Garvin KL, Kessinger MA, et al. Changes in human bone marrow fat content associated with changes in hematopoietic stem cell numbers and cytokine levels with aging. J Anat. (2011) 219:574-81. doi: 10.1111/j.1469-7580.2011.01423.x

33. Robles H, Park S, Joens MS, Fitzpatrick JAJ, Craft CS, Scheller EL. Characterization of the bone marrow adipocyte niche with three-dimensional electron microscopy. Bone (2018). doi: 10.1016/j.bone.2018.01.020. [Epub ahead of print].

34. DiMascio L, Voermans C, Uqoezwa M, Duncan A, Lu D, Wu J, et al. Identification of adiponectin as a novel hemopoietic stem cell growth factor. J Immunol. (2007) 178:3511-20. doi: 10.4049/jimmunol.178.6.3511

35. Dias CC, Nogueira-Pedro A, Tokuyama PY, Martins MN, Segreto HR, Buri MV, et al. A synthetic fragment of leptin increase hematopoietic stem cell population and improve its engraftment ability. J Cell Biochem. (2015) 116:1334-40. doi: 10.1002/jcb.25090

36. Bennett BD, Solar GP, Yuan JQ, Mathias J, Thomas GR, Matthews W. A role for leptin and its cognate receptor in hematopoiesis. Curr Biol. (1996) 6:1170-80. doi: 10.1016/S0960-9822(02)70684-2

37. Umemoto Y, Tsuji K, Yang FC, Ebihara Y, Kaneko A, Furukawa S, et al. Leptin stimulates the proliferation of murine myelocytic and primitive hematopoietic progenitor cells. Blood (1997) 90:3438-43.

38. Claycombe K, King LE, Fraker PJ. A role for leptin in sustaining lymphopoiesis and myelopoiesis. Proc Natl Acad Sci USA. (2008) 105:201721. doi: $10.1073 /$ pnas.0712053105

39. Shimozato T, Kincade PW. Prostaglandin E(2) and stem cell factor can deliver opposing signals to B lymphocyte precursors. Cell Immunol. (1999) 198:21-9. doi: 10.1006/cimm.1999.1575

40. Yokota T, Meka CS, Kouro T, Medina KL, Igarashi H, Takahashi M, et al. Adiponectin, a fat cell product, influences the earliest lymphocyte precursors in bone marrow cultures by activation of the cyclooxygenaseprostaglandin pathway in stromal cells. J Immunol. (2003) 171:5091-9. doi: 10.4049/jimmunol.171.10.5091

41. Poloni A, Maurizi G, Serrani F, Mancini S, Zingaretti MC, Frontini $A$, et al. Molecular and functional characterization of human bone marrow adipocytes. Exp Hematol. (2013) 41:558-566.e2. doi: 10.1016/j.exphem.2013.02.005

42. Maeda K, Okubo K, Shimomura I, Funahashi T, Matsuzawa Y, Matsubara K. cDNA cloning and expression of a novel adipose specific collagen-like factor, apM1 (adipose most abundant gene transcript 1). 1996. Biochem Biophys Res Commun. (2012) 425:556-9. doi: 10.1016/j.bbrc.2012.08.023 
43. Zhang Y, Proenca R, Maffei M, Barone M, Leopold L, Friedman JM. Positional cloning of the mouse obese gene and its human homologue. Nature (1994) 372:425-32. doi: 10.1038/372425a0

44. Laharrague P, Larrouy D, Fontanilles AM, Truel N, Campfield A, Tenenbaum R, et al. High expression of leptin by human bone marrow adipocytes in primary culture. Faseb J. (1998) 12:747-52. doi: 10.1096/fasebj.12.9.747

45. Tartaglia LA, Dembski M, Weng X, Deng N, Culpepper J, Devos R, et al. Identification and expression cloning of a leptin receptor, OB-R. Cell (1995) 83:1263-71. doi: 10.1016/0092-8674(95)90151-5

46. Tartaglia LA. The leptin receptor. J Biol Chem. (1997) 272:6093-6. doi: $10.1074 /$ jbc.272.10.6093

47. Tavassoli M, Maniatis A, Crosby WH. Induction of sustained hemopoiesis in fatty marrow. Blood (1974) 43:33-8.

48. Naveiras O, Nardi V, Wenzel PL, Hauschka PV, Fahey F, Daley GQ. Bone-marrow adipocytes as negative regulators of the haematopoietic microenvironment. Nature (2009) 460:259-63. doi: 10.1038/nature08099

49. Lu W, Wang W, Wang S, Feng Y, Liu K. Rosiglitazone promotes bone marrow adipogenesis to impair myelopoiesis under stress. PLoS ONE (2016) 11:e0149543. doi: 10.1371/journal.pone.0149543

50. Yamazaki K, Allen TD. Ultrastructural and morphometric alterations in bone marrow stromal tissue after 7 Gy irradiation. Blood Cells (1991) 17:527-49.

51. Glettig DL, Kaplan DL. Extending human hematopoietic stem cell survival in vitro with adipocytes. Biores Open Access (2013) 2:179-85. doi: 10.1089/biores.2013.0006

52. Spindler TJ, Tseng AW, Zhou X, Adams GB. Adipocytic cells augment the support of primitive hematopoietic cells in vitro but have no effect in the bone marrow niche under homeostatic conditions. Stem Cells Dev. (2014) 23:434-41. doi: 10.1089/scd.2013.0227

53. Zhou BO, Yu H, Yue R, Zhao Z, Rios JJ, Naveiras O, et al. Bone marrow adipocytes promote the regeneration of stem cells and haematopoiesis by secreting SCF. Nat Cell Biol. (2017) 19:891-903. doi: 10.1038/ncb3570

54. Adler BJ, Green DE, Pagnotti GM, Chan ME, Rubin CT. High fat diet rapidly suppresses $B$ Lymphopoiesis by disrupting the supportive capacity of the bone marrow niche. PLoS ONE (2014) 9:e90639. doi: 10.1371/journal.pone.0090639

55. Pang WW, Price EA, Sahoo D, Beerman I, Maloney WJ, Rossi DJ, et al. Human bone marrow hematopoietic stem cells are increased in frequency and myeloid-biased with age. Proc Natl Acad Sci USA. (2011) 108:20012-7. doi: 10.1073/pnas.1116110108

56. Rossi DJ, Bryder D, Zahn JM, Ahlenius H, Sonu R, Wagers AJ, et al. Cell intrinsic alterations underlie hematopoietic stem cell aging. Proc Natl Acad Sci USA. (2005) 102:9194-9. doi: 10.1073/pnas.0503280102

57. Bilwani FA, Knight KL. Adipocyte-derived soluble factor(s) inhibits early stages of B Lymphopoiesis. J Immunol. (2012) 189:4379-86. doi: 10.4049/jimmunol.1201176

58. Kennedy DE, Knight KL. Inhibition of B Lymphopoiesis by adipocytes and IL-1-producing myeloid-derived suppressor cells. J Immunol. (2015) 195:2666-74. doi: 10.4049/jimmunol.1500957

59. Kennedy DE, Knight KL. Inflammatory changes in bone marrow microenvironment associated with declining B Lymphopoiesis. J Immunol. (2017) 198:3471-9. doi: 10.4049/jimmunol.1601643

60. Vandanmagsar B, Youm YH, Ravussin A, Galgani JE, Stadler K, Mynatt RL, et al. The NLRP3 inflammasome instigates obesity-induced inflammation and insulin resistance. Nat Med. (2011) 17:179-88. doi: 10.1038/nm.2279

61. Salminen A, Kaarniranta K, Kauppinen A. Inflammaging: disturbed interplay between autophagy and inflammasomes. Aging (2012) 4:166-75. doi: 10.18632/aging.100444

62. Youm YH, Kanneganti TD, Vandanmagsar B, Zhu X, Ravussin A, Adijiang A, et al. The Nlrp3 inflammasome promotes age-related thymic demise and immunosenescence. Cell Rep. (2012) 1:56-68. doi: 10.1016/j.celrep.2011.11.005

63. Baker AH, Wu TH, Bolt AM, Gerstenfeld LC, Mann KK, Schlezinger JJ. From the cover: tributyltin alters the bone marrow microenvironment and suppresses B cell development. Toxicol Sci. (2017) 158:63-75. doi: 10.1093/toxsci/kfx067

64. Schlezinger JJ, Jensen BA, Mann KK, Ryu HY, Sherr DH. Peroxisome proliferator-activated receptor gamma-mediated NF-kappa B activation and apoptosis in pre-B cells. J Immunol. (2002) 169:6831-41. doi: 10.4049/jimmunol.169.12.6831

65. Belaid-Choucair Z, Lepelletier Y, Poncin G, Thiry A, Humblet C, Maachi $\mathrm{M}$, et al. Human bone marrow adipocytes block granulopoiesis through neuropilin-1-induced granulocyte colony-stimulating factor inhibition. Stem Cell. (2008) 26:1556-64. doi: 10.1634/stemcells.2008-0068

66. Nakamura M, Harigaya K, Watanabe Y. Correlation between production of colony-stimulating activity (CSA) and adipose conversion in a murine marrow-derived preadipocyte line (H-1/A). Proc Soc Exp Biol Med. (1985) 179:283-7. doi: 10.3181/00379727-179-42097

67. Bathija A, Davis S, Trubowitz S. Marrow adipose tissue: response to erythropoiesis. Am J Hematol. (1978) 5:315-21. doi: 10.1002/ajh.2830050406

68. Payne MWC, Uhthoff HK, Trudel G. Anemia of immobility: Caused by adipocyte accumulation in bone marrow. Med Hypotheses (2007) 69:778-86. doi: 10.1016/j.mehy.2007.01.077

69. Yokoyama T, Etoh T, Kitagawa H, Tsukahara S, Kannan Y. Migration of erythroblastic islands toward the sinusoid as erythroid maturation proceeds in rat bone marrow. J Vet Med Sci. (2003) 65:449-52. doi: 10.1292/jvms.65.449

70. Manwani D, Bieker JJ. The erythroblastic island. Curr Top Dev Biol. (2008) 82:23-53. doi: 10.1016/S0070-2153(07)00002-6

71. Tavassoli M. Marrow adipose cells. Histochemical identification of labile and stable components. Arch Pathol Lab Med. (1976) 100:16-8.

72. Suresh S, Caban Alvarez J, Noguchi CT. Erythropoietin eliminates increased bone marrow adiposity and alters bone features in obese mice. In: $59^{\text {th }}$ ASH Annual Meeting \&Exposition. Atlanta, GA: American Society of Hematology (2017). 3778 p.

73. Konopleva M, Mikhail A, Estrov Z, Zhao S, Harris D, Sanchez-Williams G, et al. Expression and function of leptin receptor isoforms in myeloid leukemia and myelodysplastic syndromes: proliferative and anti-apoptotic activities. Blood (1999) 93:1668-76.

74. Tabe Y, Konopleva M, Munsell MF, Marini FC, Zompetta C, McQueen T, et al. PML-RARalpha is associated with leptin-receptor induction: the role of mesenchymal stem cell-derived adipocytes in APL cell survival. Blood (2004) 103:1815-22. doi: 10.1182/blood-2003-03-0802

75. Behan JW, Yun JP, Proektor MP, Ehsanipour EA, Arutyunyan A, Moses AS, et al. Adipocytes impair leukemia treatment in mice. Cancer Res. (2009) 69:7867-74. doi: 10.1158/0008-5472.CAN-09-0800

76. Ehsanipour EA, Sheng X, Behan JW, Wang X, Butturini A, Avramis VI, et al. Adipocytes cause leukemia cell resistance to Lasparaginase via release of glutamine. Cancer Res. (2013) 73:2998-3006. doi: 10.1158/0008-5472.CAN-12-4402

77. Sheng X, Tucci J, Parmentier JH, Ji L, Behan JW, Heisterkamp N, et al. Adipocytes cause leukemia cell resistance to daunorubicin via oxidative stress response. Oncotarget (2016) 7:73147-59. doi: 10.18632/oncotarget.12246

78. Fornari FA, Randolph JK, Yalowich JC, Ritke MK, Gewirtz DA. Interference by doxorubicin with DNA unwinding in MCF-7 breast tumor cells. Mol Pharmacol. (1994) 45:649-56.

79. Tung S, Shi Y, Wong K, Zhu F, Gorczynski R, Laister RC, et al. PPARalpha and fatty acid oxidation mediate glucocorticoid resistance in chronic lymphocytic leukemia. Blood (2013) 122:969-80. doi: 10.1182/blood-2013-03-489468

80. Shafat MS, Oellerich T, Mohr S, Robinson SD, Edwards DR, Marlein $\mathrm{CR}$, et al. Leukemic blasts program bone marrow adipocytes to generate a protumoral microenvironment. Blood (2017) 129:1320-32. doi: 10.1182/blood-2016-08-734798

81. Lu W, Weng W, Zhu Q, Zhai Y, Wan Y, Liu H, et al. Small bone marrow adipocytes predict poor prognosis in acute myeloid leukemia. Haematologica (2018) 103:e21-4. doi: 10.3324/haematol.2017.173492

82. Lu W, Wan Y, Li Z, Zhu B, Yin C, Liu H, et al. Growth differentiation factor 15 contributes to marrow adipocyte remodeling in response to the growth of leukemic cells. J Exp Clin Cancer Res. (2018) 37:66. doi: 10.1186/s13046-018-0738-y

83. Liu H, Zhai Y, Zhao W, Wan Y, Lu W, Yang S, et al. Consolidation chemotherapy prevents relapse by indirectly regulating bone marrow adipogenesis in patients with acute myeloid leukemia. Cell Physiol Biochem. (2018) 45:2389-400. doi: 10.1159/000488225 
84. Boyd AL, Reid JC, Salci KR, Aslostovar L, Benoit YD, Shapovalova Z, et al. Acute myeloid leukaemia disrupts endogenous myelo-erythropoiesis by compromising the adipocyte bone marrow niche. Nat Cell Biol. (2017) 19:1336-47. doi: 10.1038/ncb3625

85. Caers J, Deleu S, Belaid Z, De Raeve H, Van Valckenborgh E, De Bruyne E, et al. Neighboring adipocytes participate in the bone marrow microenvironment of multiple myeloma cells. Leukemia (2007) 21:1580-4. doi: 10.1038/sj.leu.2404658

86. Alexandrakis MG, Passam FH, Sfiridaki A, Pappa CA, Moschandrea JA, Kandidakis E, et al. Serum levels of leptin in multiple myeloma patients and its relation to angiogenic and inflammatory cytokines. Int J Biol Markers (2004) 19:52-7. doi: 10.1177/172460080401900107

87. Kumar S, Greipp PR, Haug J, Kline M, Chng WJ, Blood E, et al. Gene expression profiling of myeloma cells at diagnosis can predict response to therapy with thalidomide and dexamethasone combination. In: $47^{\text {th }} A S H$ Annual Meeting \& Exposition. Atlanta, GA: American Society of Hematology (2005). 508 p.

88. Liu Z, Xu J, He J, Liu H, Lin P, Wan X, et al. Mature adipocytes in bone marrow protect myeloma cells against chemotherapy through autophagy activation. Oncotarget (2015) 6:34329-41. doi: 10.18632/oncotarget.6020

89. Pang J, Shi Q, Liu Z, He J, Liu H, Lin P, et al. Resistin induces multidrug resistance in myeloma by inhibiting cell death and upregulating ABC transporter expression. Haematologica (2017) 102:1273-80. doi: $10.3324 /$ haematol.2016.154062

90. Fain JN, Cheema PS, Bahouth SW, Lloyd HM. Resistin release by human adipose tissue explants in primary culture. Biochem Biophys Res Commun. (2003) 300:674-8. doi: 10.1016/S0006-291X(02)02864-4

91. Shipounova IN, Petrova TV, Svinareva DA, Momotuk KS, Mikhailova EA, Drize NI. Alterations in hematopoietic microenvironment in patients with aplastic anemia. Clin Transl Sci. (2009) 2:67-74. doi: 10.1111/j.1752-8062.2008.00074.x

92. Chen YH, Yeh FL, Yeh SP, Ma HT, Hung SC, Hung MC, et al. Myocyte enhancer factor-2 interacting transcriptional repressor (MITR) is a switch that promotes osteogenesis and inhibits adipogenesis of mesenchymal stem cells by inactivating peroxisome proliferator-activated receptor gamma-2. J Biol Chem. (2011) 286:10671-80. doi: 10.1074/jbc.M110.199612

93. Hoshiba T, Kawazoe N, Chen G. The balance of osteogenic and adipogenic differentiation in human mesenchymal stem cells by matrices that mimic stepwise tissue development. Biomaterials (2012) 33:2025-31. doi: 10.1016/j.biomaterials.2011.11.061

94. Tripathy NK, Singh SP, Nityanand S. Enhanced adipogenicity of bone marrow mesenchymal stem cells in aplastic anemia. Stem Cells Int. (2014) 2014:276862. doi: 10.1155/2014/276862

95. Song Y, Li N, Liu Y, Fang B. Improved outcome of adults with aplastic anaemia treated with arsenic trioxide plus ciclosporin. Br J Haematol. (2013) 160:266-9. doi: 10.1111/bjh.12110

96. Li N, Song Y, Zhou J, Fang B. Arsenic trioxide improves hematopoiesis in refractory severe aplastic anemia. J Hematol Oncol. (2012) 5:61. doi: 10.1186/1756-8722-5-61

97. Wang HY, Ding TL, Xie Y, Xu XP, Yu L, Chen T. [Osteogenic and adipogenic differentiation of bone marrow-derived mesenchymal stem cells in patients with aplastic anemia]. Zhonghua Nei Ke Za Zhi (2009) 48:39-43.
98. Zhao J, Wang C, Song Y, Fang B. Arsenic trioxide and microRNA-204 display contrary effects on regulating adipogenic and osteogenic differentiation of mesenchymal stem cells in aplastic anemia. Acta Biochim Biophys Sin (2014) 46:885-93. doi: 10.1093/abbs/gmu082

99. Takada I, Kouzmenko AP, Kato S. Wnt and PPARgamma signaling in osteoblastogenesis and adipogenesis. Nat Rev Rheumatol. (2009) 5:442-7. doi: 10.1038/nrrheum.2009.137

100. Zhang N, Dai YL, Huang LF, Liu WL. [Therapeutic effect of lithium chloride combined with cyclosporine A on mouse model with aplastic anemia]. Zhongguo Shi Yan Xue Ye Xue Za Zhi. (2012) 20:654-7.

101. Tsai FY, Keller G, Kuo FC, Weiss M, Chen J, Rosenblatt M, et al. An early haematopoietic defect in mice lacking the transcription factor GATA-2. Nature (1994) 371:221-6. doi: 10.1038/371221a0

102. Ling KW, Ottersbach K, van Hamburg JP, Oziemlak A, Tsai FY, Orkin $\mathrm{SH}$, et al. GATA-2 plays two functionally distinct roles during the ontogeny of hematopoietic stem cells. J Exp Med. (2004) 200:871-82. doi: 10.1084/jem.20031556

103. Rodrigues NP, Janzen V, Forkert R, Dombkowski DM, Boyd AS, Orkin SH, et al. Haploinsufficiency of GATA-2 perturbs adult hematopoietic stem-cell homeostasis. Blood (2005) 106:477-84. doi: 10.1182/blood-2004-08-2989

104. Fujimaki S, Harigae H, Sugawara T, Takasawa N, Sasaki T, Kaku M. Decreased expression of transcription factor GATA-2 in haematopoietic stem cells in patients with aplastic anaemia. Br J Haematol. (2001) 113:52-7. doi: 10.1046/j.1365-2141.2001.02736.x

105. Zeng W, Chen G, Kajigaya S, Nunez O, Charrow A, Billings EM, et al. Gene expression profiling in CD34 cells to identify differences between aplastic anemia patients and healthy volunteers. Blood (2004) 103:325-32. doi: 10.1182/blood-2003-02-0490

106. Tong Q, Tsai J, Hotamisligil GS. GATA transcription factors and fat cell formation. Drug News Perspect. (2003) 16:585-8. doi: 10.1358/dnp.2003.16.9.829340

107. Xu Y, Takahashi Y, Wang Y, Hama A, Nishio N, Muramatsu H, et al. Downregulation of GATA-2 and overexpression of adipogenic genePPARgamma in mesenchymal stem cells from patients with aplastic anemia. Exp Hematol. (2009) 37:1393-9. doi: 10.1016/j.exphem.2009.09.005

108. Kamata M, Okitsu Y, Fujiwara T, Kanehira M, Nakajima S, Takahashi T, et al. GATA2 regulates differentiation of bone marrow-derived mesenchymal stem cells. Haematologica (2014) 99:1686-96. doi: 10.3324/haematol.2014. 105692

109. Birbrair A, Frenette PS. Niche heterogeneity in the bone marrow. Ann N Y Acad Sci. (2016) 1370:82-96. doi: 10.1111/nyas.13016

Conflict of Interest Statement: The authors declare that the research was conducted in the absence of any commercial or financial relationships that could be construed as a potential conflict of interest.

Copyright (c) 2018 Wang, Leng and Gong. This is an open-access article distributed under the terms of the Creative Commons Attribution License (CC BY). The use, distribution or reproduction in other forums is permitted, provided the original author(s) and the copyright owner(s) are credited and that the original publication in this journal is cited, in accordance with accepted academic practice. No use, distribution or reproduction is permitted which does not comply with these terms. 